\title{
PENERAPAN ALGORITMA GENETIK UNTUK OPTIMASI TRANSFER DAYA PADA SISTEM SENSOR GAS METANA
}

\author{
Muthmainnah $^{1)}$, Melania Suweni Muntini ${ }^{2)}$.
}

\begin{abstract}
Abstrak: Pada pengukuran perubahan gejala fisis digunakan sensor yang dirangkai dengan pengkondisi sinyal dan komponen elektronik lain. Pemilihan pengkondisi sinyal sangat penting karena menentukan efektifitas transfer daya antara sensor dan pengkondisi sinyal. Transfer daya optimum akan terjadi pada saat nilai resistansi sensor $\left(\mathrm{R}_{\mathrm{S}}\right)$ sama dengan resistansi beban $\left(\mathrm{R}_{\mathrm{L}}\right)$.

Pada makalah penelitian ini disajikan hasil optimasi transfer daya yang bertujuan untuk mengoptimumkan daya yang ditransfer dari sensor gas metana ke pengkondisi sinyal. Metode optimasi yang digunakan adalah algoritma genetik dengan tegangan sensor $\left(\mathrm{V}_{\mathrm{S}}\right)$ dan resistansi beban $\left(\mathrm{R}_{\mathrm{L}}\right)$ sebagai kromosom. Pemilihan probabilitas crossover 0,8 dan probabilitas mutasi 0,2. Pada penelitian ini jumlah populasi yang digunakan adalah 1000 dan 200 generasi. Hasil optimasi ditentukan dengan fungsi fitness yang menggambarkan daya maksimum dengan nilai optimum tegangan sensor $\left(\mathrm{V}_{\mathrm{S}}\right)$ 4,724 Volt dan resistansi beban $\left(\mathrm{R}_{\mathrm{L}}\right)$ 450,6556 Ohm. Kondisi tersebut dicapai pada generasi ke 46 dan daya yang ditransfer adalah 0,1981 Watt.

Kata Kunci : Algoritma genetik, Generasi, Optimasi, Pengkondisi sinyal, Transfer daya.
\end{abstract}

\section{PENDAHULUAN}

Sensor merupakan suatu peralatan yang berfungsi untuk mendeteksi gejalagejala atau sinyal-sinyal yang berasal dari perubahan suatu energi seperti energi listrik, energi fisika, energi kimia, energi biologi, energi mekanik dan sebagainya. Sensor yang sering ditemui dipasaran kebanyakan belum dapat langsung digunakan, sehingga harus dirangkai dengan komponen-komponen elektronik lain. Komponen-komponen yang dimaksud adalah pengkondisi sinyal, mikrokontroler dan display sebagai tampilan hasil sensing.

Pada sistem sensor pemilihan pengkondisi sinyal sangat penting karena menentukan efektifitas transfer daya yang terjadi antara sensor dan pengkondisi sinyal. Transfer daya optimum akan terjadi pada saat resistansi sensor $\left(R_{S}\right)$ sama dengan resistansi beban $\left(\mathrm{R}_{\mathrm{L}}\right)$. Pemilihan nilai resistansi beban $\left(\mathrm{R}_{\mathrm{L}}\right)$ harus dilakukan secara cermat karena disamping dayanya harus maksimum, tegangan yang keluar dari pengkondisi sinyal juga harus dapat dibaca oleh mikrokontroler. Upaya untuk mengoptimalkan transfer daya perlu dilakukan dengan batasan resistansi beban $\left(\mathrm{R}_{\mathrm{L}}\right)$ yang terdapat pada sistem sensor.

Penelitian optimasi transfer daya pada sensor gas telah dilakukan oleh Muwahidah Hasanah (2009). Metode yang digunakan adalah metode pendekatan linear.

\footnotetext{
1,2 Jurusan Fisika Pascasarjana FMIPA Institut Teknologi Sepuluh Nopember (ITS) Surabaya
} 
Metode optimasi ini berkerja secara deterministik. Salah satu metode optimasi yang sedang dikembangkan adalah algoritma genetik.

Algoritma genetik adalah suatu model rekayasa hasil evolusi tiruan yang diilhami oleh perkembangan teknik pembiakan genetik secara alamiah untuk dapat menangani penyelesaian berbagai masalah pelacakan. Algoritma genetik sangat baik diterapkan untuk masalah optimasi dan dapat digunakan untuk mencari pemecahan optimum suatu fungsi multi variabel.

\section{KAJIAN TEORI}

\section{A. Sensor Gas}

Sensor gas merupakan tranduser yang mampu mendeteksi perubahan kondisi lingkungan dan kemudian menghasilkan sinyal listrik yang besarnya proporsional dengan konsentrasi gas. Tipe-tipe sensor gas yang telah dikembangkan antara lain sensor elektrokimia, sensor foto ionisasi dan katalis, sensor zat padat, dan sensor infra merah. Pengembangan sensor gas digunakan untuk memonitor atmosfer melalui tekanan parsial oksigen sebagai parameter utama dan unsur-unsur atmosfer dalam konsentrasi yang relatif kecil pada kondisi udara normal.

\section{B. Pengkondisi Sinyal Sistem Sensor}

Pengkondisi sinyal adalah rangkaian elektronik yang dapat digunakan untuk mendapatkan parameter fisik dan kemudian diubah menjadi sinyal keluaran yang diperlukan (Muwahidah, 2009). Secara umum tugas pengkondisi sinyal adalah penguatan (amplification), penyaringan (filter), dan linearisasi. Tipe yang spesifik dari pengkondisi sinyal tergantung pada tipe dari sumber masukan yang digunakan dan karakteristik sinyal keluaran yang dihasilkan.

Tipe pengkondisi sinyal yang sering digunakan adalah inverting dan noninverting. Inverting digunakan untuk menguatkan tegangan pada masukan serta membalik hasil penguatan tersebut, jadi keluaran dari rangkaian ini selalu memiliki polaritas yang berlawananan dengan sinyal masukannya. Non-inverting digunakan untuk menguatkan tegangan tanpa membalik hasil penguatannya, jadi keluaran dari rangkaiannya sefase.

\section{Algoritma Genetik}

Algoritma genetik muncul diinspirasi oleh teori-teori dalam ilmu biologi, sehingga banyak istilah dan konsep biologi yang digunakan dalam Algoritma genetik. Sesuai dengan namanya, proses yang terjadi dalam algoritma genetik sama dengan yang terjadi pada evolusi biologi.

Menutut DE Goldberg (1989), algoritma genetik adalah suatu algoritma pencarian (searching) yang didasarkan pada mekanisme seleksi alam. Tujuannya untuk menentukan struktur-struktur yang disebut dengan individu berkualitas tinggi dalam 
suatu domain yang disebut populasi untuk mendapatkan solusi terbaik suatu persoalan. Komponen-komponen dalam algoritma genetik tersebut adalah sebagai berikut:

\section{a. Pengkodean}

Terdapat tiga cara yang paling umum digunakan dalam pengkodean, yaitu:

1. Binary encoding, untuk pengkodean binary encoding setiap gen diberi nilai 0 atau 1.

2. Real number, pada pengkodean real number nilai gen berada dalam interval $(0, \mathrm{R})$ dengan $\mathrm{R}$ adalah bilangan real positif dan biasanya $\mathrm{R}=1$.

3. Discreet decimal decoding. Setiap gen bernilai salah satu bilangan bulat dalam interval $(0,9)$.

\section{b. Fungsi Fitness}

Fungsi fitness bermanfaat untuk mengevaluasi kandidat solusi sistem yang dimodelkan. Pada evolusi alam, individu yang memiliki nilai fitness rendah akan mati.

\section{c. Seleksi}

Seleksi dilakukan untuk menentukan individu-individu mana saja yang akan dipilih untuk melakukan rekombinasi dan bagaimana offspring yang terbentuk dari individu-individu terpilih tersebut. Dalam algoritma genetik terdapat dua macam seleksi, yaitu roda roulette (roulette whell selection) dan rank based fitness.

-Roda roulette digunakan untuk menentukan individu orang tua yang akan dikenai operasi genetik. Sesuai dengan namanya, metode ini menirukan permainan roulettewheel dengan masing-masing kromosom menempati potongan lingkaran pada roda roulette secara proporsional sesuai dengan nilai fitness-nya (Triswantoro Putro, 2007). -Rank based fitness fitness biasanya digunakan untuk menentukan generasi baru setelah proses operasi genetik diterapkan dalam individu-individu orang tua sehingga lahirlah individu-individu baru (D.Quagliarella, 1998). Pada metode ini populasi diurutkan menurut ranking nilai fitness masing-masing individu.

\section{d. Pindah silang (crossover)}

Salah satu komponen penting dalam algoritma genetik adalah crossover atau pindah silang. Crossover dilakukan untuk menukarkan informasi antar kromosom.

\section{e. Mutasi}

Mutasi adalah komponen dalam algoritma genetik yang bisa memodifikasi satu gen atau lebih dalam kromosom yang sama sehingga dapat menyebabkan terciptanya individu baru.

\section{f. Elitisme}

Pada penyeleksian kromosom dilakukan dengan random, sehingga tidak ada jaminan bahwa suatu individu bernilai fitness tertinggi akan selalu terpilih, mungkin saja individu tersebut akan rusak (nilai fitness-nya menurun) karena proses pindah 
silang. Untuk menjaga agar individu bernilai fitness tersebut tidak hilang selama evolusi, maka perlu dibuat satu atau beberapa kopinya. Prosedur ini disebut dengan elitisme.

\section{PEMBAHASAN}

\section{A. Sensor Gas Metana}

Sensor gas metana yang digunakan adalah TGS 2611 keluaran Figaro. Sensor ini mempunyai sensitivitas dan selektifitas yang sangat baik terhadap gas metana. Material sensor gas terbuat dari bahan semikonduktor sehingga perlu dipanaskan agar dapat bekerja dengan optimal. Sensor gas berbahan metal oksida mempunyai fungsi kerja pada $250^{\circ} \mathrm{C}-400^{\circ} \mathrm{C}$. Ketika sensor didekatkan dengan gas metana, maka gas metana akan mereduksi muatan negatif oksigen, sehingga resistansi sensor menurun.

\section{B. Pengkondisi Sinyal Sistem Sensor}

Pengkondisi sinyal yang digunakan pada sensor gas adalah penguat non inverting. Penguat non inverting adalah penguat sinyal dengan tegangan keluaran yang sefase dengan sinyal masukan. Sinyal masukan disambungkan ke kaki tak membalik (+) dan masukan membalik (-) dibumikan. Tanda (+) dan (-) pada masukan bukan menunjukkan orientasi tegangan tetapi untuk menunjukkan adanya ketertinggalan fase. Rangkaian penguat non inverting ditunjukkan oleh Gambar 3.1.

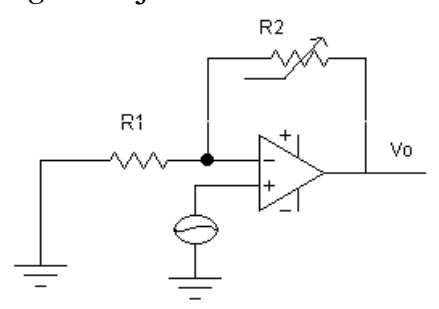

Gambar 1. Rangkaian Penguat Non Inverting

Tegangan pada masukan membalik sama dengan tegangan masukan sumber $\left(\mathrm{V}_{\mathrm{i}}\right)$, yang juga sama dengan tegangan dari sebuah pembagi tegangan antara $\mathrm{V}_{\mathrm{o}}$ dan ground pada persamaan

$$
V_{\text {out }}=\frac{R_{2}+R_{1}}{R_{1}} \times V_{\text {in }}
$$

Rangkaian sensor dan pengkondisi sinyal ditunjukkan oleh Gambar 2.

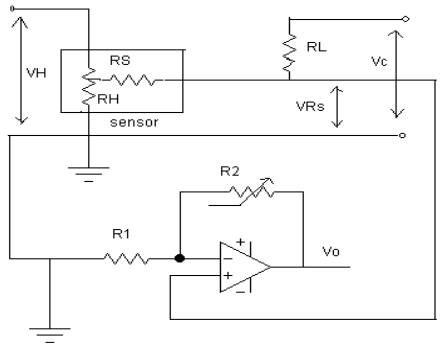

Gambar 2 Rangkaian Sensor dengan Penguat Tak Membalik 
Keluaran dari penguat dihubungkan ke mikrokontroler sehingga terjadi transfer daya dari sistem sensor ke pengkondisi sinyal. Optimasi dilakukan untuk memperoleh transfer daya maksimum agar energi yang diterima oleh mikrokontroler adalah maksimum. Transfer daya akan maksimum jika tahanan dalam $\left(\mathrm{R}_{\mathrm{L}}\right)$ sama dengan tahanan sensor $\left(\mathrm{R}_{\mathrm{S}}\right)$ dan $\mathrm{P}$ merupakan fungsi $\mathrm{R}_{\mathrm{S}}$, maka untuk mencari nilai maksimum $\mathrm{P}$ adalah

$$
P=i^{2} R_{S}=\left(\frac{V_{R S}}{\frac{R_{S} R_{L}}{R_{S}+R_{L}}}\right)^{2} R_{S}=\frac{V_{R S}{ }^{2}\left(R_{S}+R_{L}\right)^{2}}{R_{S} R_{L}^{2}}
$$

$\mathrm{P}$ akan optimum jika

$$
\begin{aligned}
& \frac{d P}{d R_{S}}=0 \\
& \frac{d P}{d R_{S}}=\frac{V_{R S}^{2}\left(R_{S}^{2} R_{L}^{2}-R_{L}^{4}\right)}{R_{S}^{2} R_{L}^{4}}=0
\end{aligned}
$$

Sehingga $: R_{L}=R_{S}$

Daya maksimumnya yaitu:

$$
P_{S}=\frac{4 V_{R S}^{2}}{\left(R_{L}\right)}
$$

\section{Algoritma Genetik}

Optimasi transfer daya dilakukan dengan mempertimbangan batasan rangkaian pengkondisi sinyal sistem sensor yang berupa resistansi beban selama proses sensing berlangsung. Algoritma genetik merupakan salah satu metode optimasi probabilistik heuristik yang dididasarkan pada evolusi genetik alami untuk menyelesaikan berbagai macam masalah optimasi melalui pelacakan.

Diagram alir proses optimasi dengan menggunakan algoritma genetik diperlihatkan dalam Gambar 3. 


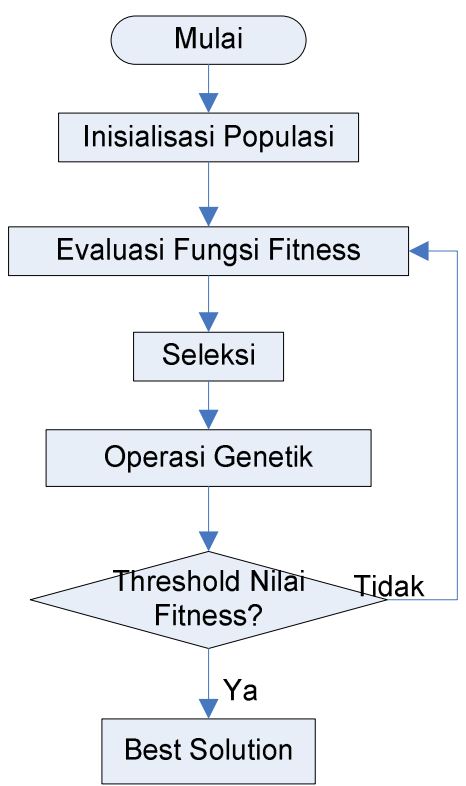

Gambar 3. Diagram Alir Algoritma Genetik

\section{a. Populasi mula-mula}

Pada penelitian ini akan dilakukan optimasi transfer daya dengan mempertimbangan batasan pada rangkaian pengkondisi sinyal sistem sensor yang berupa tegangan sensor dan resistansi beban selama proses sensing berlangsung. Batasan-batasan tersebut adalah:

$$
\begin{gathered}
R_{L}-450 \geq 0 \\
0<V_{R S}<5
\end{gathered}
$$

Pada penelitian ini kromosom yang dibentuk adalah tegangan sensor $\left(\mathrm{V}_{\mathrm{RS}}\right)$ dan tahanan dalam $\left(\mathrm{R}_{\mathrm{L}}\right)$. Pengkodeaan dilakukan dengan bilangan real yang dibangkitkan secara random berdasarkan batasan-batasannya.

\section{b. Penentuan fungsi fitness.}

Fungsi fitness berfungsi untuk mengevaluasi setiap individu dalam suatu populasi. Fungsi fitness-nya adalah

$$
f=\frac{1}{(S D+a)}
$$

a bernilai 1 yang berfungsi untuk menghindari terjadinya pembagian terhadap nol oleh fungsi fitness. Untuk standar deviasi yang kecil maka fungsi fitness akan mendekati 1. Makin tinggi nilai fitnessnya makin besar peluang mendapatkan set solusi tersebut untuk dipilih menjadi nilai transfer daya optimum.

\section{c. Evaluasi}

Proses seleksi dengan menggunakan metode roulette wheel, harus terlebih dahulu mencari probabilitas akumulatif $\left(\mathrm{C}_{\mathrm{i}}\right)$ dari probabilitas seleksinya $\left(\mathrm{P}_{\mathrm{i}}\right)$.

$$
C_{i}=\sum_{i=1}^{n} P_{i}
$$


Setelah dihitung nilai komulatif probabilitasnya, maka proses seleksi menggunakan metode ini dapat dilakukan. Prosesnya adalah dengan membangkitkan bilangan acak $R_{i}$ dalam ruang 0 - 1 . Suatu induk akan dipilih sebagi orang tua jika memenuhi persyaratan:

$$
C_{i-1}<R_{i}<C_{i}
$$

\section{d. Operasi genetik}

Dalam algoritma genetik ada dua macam operator genetik, yaitu crossover dan mutasi (Zbigniew Michalewicz, 1999). Kedua operator genetik ini berkerja pada probabilitas tertentu, yaitu probabilitas crossover $\left(\mathrm{P}_{\mathrm{C}}\right)$ dan probabilitas mutasi $\left(\mathrm{P}_{\mathrm{M}}\right)$. Sehingga dalam suatu populasi tidak semua individu mengalami crossover atau mutasi, tetapi ada juga individu yang dapat mengalami crossover dan mutasi.

\section{Crossover}

Crossover adalah operasi pindah silang antar kromosom yang dilakukan untuk membentuk individu baru yang lebih baik. Pada kasus ini $\mathrm{P}_{\mathrm{C}}$ yang dipilih adalah 0,6. Pada pengkodean secara aritmatik crossover-nya didefinisikan sebagai kombinasi linier dari dua kromosom. Misalkan $v_{1}{ }^{t}$ dan $v_{2}{ }^{t}$ adalah kromosom-kromosom yang terseleksi yang akan dicrossover-kan. Maka hasil crossover-nya adalah sebagai berikut:

$$
\begin{aligned}
& v_{1}^{t+1}=a v_{2}^{t}+(1-a) v_{1}^{t} \\
& v_{2}^{t+1}=a v_{1}^{t}+(1-a) v_{2}^{t}
\end{aligned}
$$

Nilai parameter a dapat dipilih suatu konstanta atau suatu variabel yang memiliki ketergantungan terhadap generasi.

2. Mutasi

Operator mutasi digunakan untuk melakukan modifikasi satu atau lebih nilai gen dalam kromosom yang sama, atau pergeseran gen dalam suatu kromosom. Pada permasaahan ini $\mathrm{P}_{\mathrm{M}}$ yang dipilih adalah 0,2 . Operator mutasi dapat dilakukan dengan memilih kromosom yang dimutasi. Jika $s_{v}^{t}=\left(v_{1}, v_{2}, \ldots v_{k}, \ldots . v_{m}\right)$ dan $v_{k}$ terpilih untuk bermutasi, maka hasil mutasinya adalah $s_{v}^{t}=\left(v_{1}, v_{2}, \ldots v_{k}^{\prime}, \ldots . v_{m}\right)$ dimana

$$
\begin{gathered}
v_{k}^{\prime}=\left\{\begin{array}{l}
v_{k}+\delta\left(t, u v-v_{k}\right) \\
v_{k}-\delta\left(t, v_{k}-l v\right)
\end{array}\right. \\
\delta(t, y)=y \cdot\left(1-r^{\left(1-\frac{t}{T}\right)^{b}}\right)
\end{gathered}
$$

$\mathrm{b}=$ Parameter yang menunjukkan tingkat ketergantungan pada iterasi; $\mathrm{r}=$ Bilangan acak; $\mathrm{t}=$ Generasi; $\mathrm{T}=$ Generasi maksimum; $\mathrm{lv}=$ Batas bawah; $\mathrm{uv}=$ Batas atas.

\section{e. Penentuan populasi untuk generasi berikutnya}

Setelah semua operasi genetik dilakukan maka terbentuklah individu-individu baru hasil crossover dan mutasi. Individu-individu yang terkumpul adalah individuindividu dari populasi awal, individu hasil crossover dan individu hasil mutasi. Padahal 
yang akan dievaluasi adalah individu sejumlah populasi awal, sehingga perlu dilakukan seleksi untuk menentukan individu mana yang akan dievaluasi.

Seleksi yang digunakan adalah seleksi ranking. Seleksi ranking dilakukan dengan memilih individu yang memiliki ranking 1 sampai dengan ranking sejumlah populsi awal. Individu yang memiliki ranking dibawah jumlah populasi awal tidak akan diseleksi atau dihapus.

\section{Implementasi}

Pengujian dilakukan pada jumlah populasi $1000, \mathrm{P}_{\mathrm{C}} 0,8, \mathrm{P}_{\mathrm{M}} 0,2$ dan dengan generasi maksimal adalah 200 generasi. Fitness yang dicapai adalah 0,9840 dan mulai konvergen pada generasi ke 46 dengan parameter $\mathrm{V}$ adalah 4,724 Volt dan $\mathrm{R}$ adalah 450,6556 Ohm. Pada kondisi ini daya yang ditransfer adalah 0,1981 Watt.

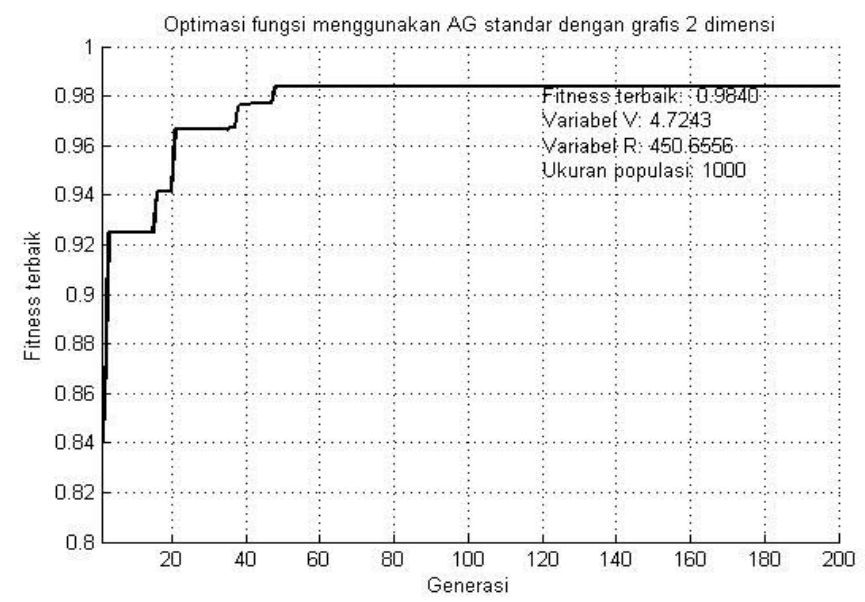

Gambar 4. Hasil algoritma genetik menggunakan matlab

\section{KESIMPULAN}

Algoritma genetik yang dijalankan untuk melakukan optimasi transfer daya memberikan simpulan bahwa:

1. Kondisi optimum terjadi pada generasi ke 46 dari 200 generasi.

2. Transfer daya optimum terjadi pada nilai tegangan $\left(\mathrm{V}_{\mathrm{RS}}\right) 4,724$ Volt dan resistansi $\left(\mathrm{R}_{\mathrm{L}}\right)$ adalah $450,6556 \mathrm{Ohm}$.

3. Daya yang ditransfer pada kondisi optimum adalah 0,1981 Watt.

\section{DAFTAR PUSTAKA}

D. Quagliarella, S. Pe'riaux, C. Poloni, 1998. Genetic Algorithm and Evolution Strategies in Engineering and Computer Science, British Library, England.

Fadlisyah, Arnawan, Faisal, 2009, Algoritma Genetik, Graha Ilmu, Yogyakarta.

Hasanah. Muwahidah, 2009, Optimasi Sistem Pengukuran Melalui Modifikasi Pengkondisi Sinyal pada Sensor Gas, ITS, Surabaya. 
Kusumadewi. Sri, Purnomo. Hadi, 2005. Penyelesaian Masalah Optimasi dengan Teknik-Teknik Heuristik, Graha Ilmu, Yogyakarta.

Michalewicz, Zbigniew, 1997, Genetic Algorithm + Data Stuctures = Evolution Program, Springer.

Suweni Muntini. Melania, 2000, Teknik Identifikasi Sistem dan Penentuan Orde Model dengan Algoritma Genetik, ITB, Bandung.

Suyanto, 2005, Algoritma Genetik dalam Matlab, Andi, Yogyakarta.

Putro, Triswantoro, 2007, Implementasi Algoritma Genetik pada Akuisisi Data Penilaian Warna Secara Online, ITS, Surabaya. 